\title{
Nonunion after an open trimalleolar ankle fracture: an extended clinical course and a novel approach to tibio-talo-calcaneal arthrodesis
}

\author{
Teuber, Henrik ; Rauer, Thomas ; Pape, Hans-Christoph ; Allemann, Florin
}

DOI: https://doi.org/10.1053/j.jfas.2020.03.025

Posted at the Zurich Open Repository and Archive, University of Zurich ZORA URL: https://doi.org/10.5167/uzh-189081

Journal Article

Accepted Version

Originally published at:

Teuber, Henrik; Rauer, Thomas; Pape, Hans-Christoph; Allemann, Florin (2021). Nonunion after an open trimalleolar ankle fracture: an extended clinical course and a novel approach to tibio-talo-calcaneal arthrodesis. Journal of Foot and Ankle Surgery, 60(2):378-381.

DOI: https://doi.org/10.1053/j.jfas.2020.03.025 


\section{Journal Pre-proof}

Nonunion after an open trimalleolar ankle fracture: an extended clinical course and a novel approach to tibio-talo-calcaneal arthrodesis

Henrik Teuber DO, Henrik Teuber DO, Thomas Rauer MD , Hans-Christoph Pape MD , Florin Allemann MD

PII: S1067-2516(20)30277-5

DOI: https://doi.org/10.1053/j.jfas.2020.03.025

Reference: YJFAS 53325

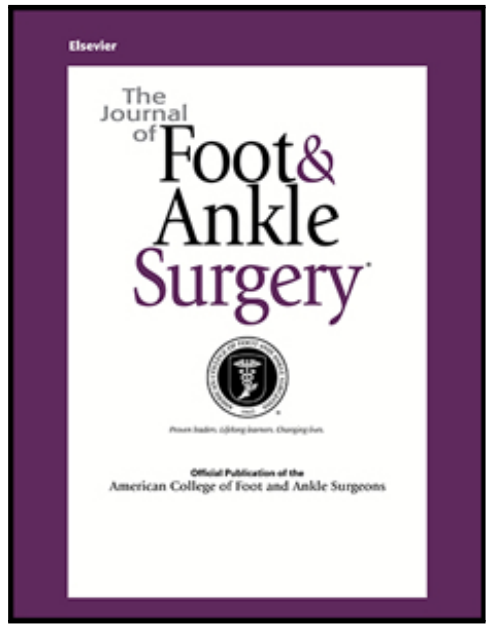

To appear in:

The Journal of Foot and Ankle Surgery

Please cite this article as: Henrik Teuber DO, Henrik Teuber DO, Thomas Rauer MD, Hans-Christoph Pape MD , Florin Allemann MD , Nonunion after an open trimalleolar ankle fracture: an extended clinical course and a novel approach to tibio-talo-calcaneal arthrodesis, The Journal of Foot and Ankle Surgery (2020), doi: https://doi.org/10.1053/j.jfas.2020.03.025

This is a PDF file of an article that has undergone enhancements after acceptance, such as the addition of a cover page and metadata, and formatting for readability, but it is not yet the definitive version of record. This version will undergo additional copyediting, typesetting and review before it is published in its final form, but we are providing this version to give early visibility of the article. Please note that, during the production process, errors may be discovered which could affect the content, and all legal disclaimers that apply to the journal pertain.

Published by Elsevier Inc. on behalf of the American College of Foot and Ankle Surgeons. 
Nonunion after an open trimalleolar ankle fracture: an extended clinical

\section{course and a novel approach to tibio-talo-calcaneal arthrodesis}

\section{Article Type:}

Case Report

\section{Keywords:}

tibio-talo-calcaneal arthrodesis, low-grade infection, Masquelet, reamer-irrigatior-aspirator, ringfixator, salvage procedure, chronic osteomyelitis, bone graft reconstruction

\section{Corresponding Author:}

Henrik Teuber, DO henrik.teuber@usz.ch

\section{Corresponding Author's Institution:}

University Hospital Zurich

Department of Trauma

Rämistrasse 100

8091 Zurich

Switzerland

\section{Order of Authors:}

Henrik Teuber, DO

Thomas Rauer, MD

Hans-Christoph Pape, MD

Florin Allemann, MD

Level of Evidence: Level IV

\section{INTRODUCTION}

After failed fixation of ankle fractures, salvage arthrodesis of the tibiotalar as well as the subtalar joint represents a good treatment option. This case report discusses the operative management of an open ankle fracture-dislocation initially managed with ORIF. After development of a nonunion and secondary loss of reduction, initial efforts to achieve tibiotalocalcaneal (TTC) arthrodesis failed. In subsequent years, a low-grade infection with partial osteomyelitic destruction of the talus developed. Successful fusion was ultimately achieved using the Masquelet technique, external ring fixation, and staged autogenous 
femoral bone graft supplementation harvested by the reamer-irrigator-aspirator (RIA, Synthes).

\section{CASE REPORT}

The patient was a healthy, non-obese 47-year-old male suffering a third degree open, displaced trimalleolar ankle fracture-dislocation after a motorcycle accident. Additionally, the patient suffered an ipsilateral first degree open forearm fracture as well as an ipsilateral first degree open patella fracture. The patient had no past medical history, was a non-smoker, non-diabetic and had no other comorbidities associated with an increased risk of infection. Alcohol overconsumption was the only relevant risk factor. Initial management included closed reduction and external fixation with irrigation, debridement and NPWT of the ankle. The forearm and patella fractures were immediately definitively managed with compression plating and a tension-band, respectively. A wide spectrum antibiotic therapy was prophylactically administered. Three days after trauma the ankle was again irrigated and debrided. After swelling subsided, the trimalleolar fracture was definitively treated through a posterolateral approach to fix the Volkmann fragment and treat the lateral malleolus with neutralization plating and lag screw-osteosynthesis. The medial malleolus was fixed with a posteromedial $1 / 3$ tubular plate and the medial soft tissue defect was treated with a microvascular gracilis flap. Postoperative healing was unspectacular with no signs of infection and no flap necrosis.

At 6 month follow-up, a nonunion with hardware failure and secondary fracture dislocation due to patient noncompliance with excessive early weight-bearing was diagnosed without renewed trauma. An allograft-interposition tibio-talar arthrodesis with a 95-degree blade plate and revision ORIF with a 1/3-tubular 
plate of the fibula was performed. A low-grade infection through multiple intraoperative biopsies was ruled out. The soft tissue flap was healed and well perfused. Unfortunately, a nonunion persisted and 16 months postoperatively the blade plate was removed and a TTC fusion with an arthrodesis nail (Stryker) and reamed tibial cancellous bone augmentation was performed. After an additional six months, fusion was not achieved, and a further revision with an anklearthrodesis plate (Synthes) medially and a 3.5mm-T-LCP laterally after nail removal was performed. Allograft adipose-derived mesenchymal stem cells combined with partially demineralized allograft bone (Allostem/ Neutromedics) were used to facilitate fusion. During this surgery, a single soft-tissue culture grew low levels of Staphylococcus lugdunensis. Antibiotic therapy with clindamycin and ciprofloxacin due to a presumed penicillin allergy was initiated for 12 weeks.

Unfortunately, 18 months later and three and a half years after initial trauma, fusion was still not achieved and the patient was largely wheel-chair bound due to painful weight-bearing and persisting ankle instability. A persisting low-grade chronic osteomyelitis due to failed fusion and extensive osteolysis of the talus was presumed. A Masquelet treatment plan with full hardware removal, meticulous bone and soft-tissue debridement, application of an external fixator and placement of an appropriate antibiotic spacer with endomedullary extension was performed. Multiple biopsies were obtained, which again showed a lowgrade Staphylococcus lugdunensis infection. Antibiotic treatment consisted of floxacillin and ciprofloxacin for 14 weeks.

Nearly four months postoperatively with no sign of infection, a well-healed soft tissue flap, and radiographic evidence of initial bony fusion of the fibula, a final revision was performed. At the time, the patient could walk a maximum of 200 
meters with two crutches. The external fixator and the cement spacer were removed. Cancellous autogenous bone graft was harvested from the ipsilateral femur using RIA. Although the infection was deemed eradicated, harvesting from the tibia was not desirable due to the fear of contaminated bone as well as previous reaming of the tibia. The bone graft was placed in the tibiotalar and subtalar joints. To limit further morbidity, despite an increased risk of renewed infection, an allograft bone block was used in lieu of an autologous bone block to fill the bony defect at the level of the talus. Renewed internal fixation was deemed too risky and the ankle was therefore definitively stabilized and compressed with a ring-fixator (True-Lok-Ring-Fixation-System; Orthofix). The patient was allowed partial weight bearing of up to $15 \mathrm{~kg}$ for three months postoperatively. Image 1 shows treatment progression from the initial injury up to and including the final TTC arthrodesis revision. After six months, the patient reported markedly decreased pain with weight-bearing and bony fusion of both joints was confirmed radiographically (Image 2). Fusion was achieved with good hindfoot alignment in slight valgus and no sign of latent infection (Image 3). The ring-fixator was removed and intensive physical therapy to further improve gait was continued. Although fusion was achieved with marked improvement in mobility and return to activities of daily living, complete weight bearing was not achieved and a slight limp with intermittent use of crutches persisted at 36-month follow-up after fusion. The clinical course is summarized in a timeline (Figure 1).

\section{DISCUSSION}

Normally, TTC arthrodesis is a rescue operation in the setting of severe destruction, posttraumatic arthritis or other complex issues of the tibiotalar and/or subtalar joints.(1) If, however, in the setting of a severe fracture about the ankle, 
multiple or major risk factors exist with a high chance of postoperative complications, a primary TTC arthrodesis may also be considered.(2-6) In the literature, persisting nonunion rates after intramedullary nail arthrodesis average about $12 \%$ with a range of zero to $43 \%$ with the subtalar joint more likely to develop a persisting nonunion.(2, 3, 5, 7, 8) The most frequent risk factors associated with failed fusion were past operations, age and higher-risk medical comorbidities.(1, 4, 9-12) Postoperative complications in open fractures of the ankle and TTC arthrodesis are common. In a study by Goebel et al. an overall complication rate of $21 \%$ was observed.(2) Hammett et al. reported an overall complication rate of $59 \%$, with $25 \%$ of them being major complications.(13) Chou et al. showed complications in $35 \%$ of patients. (4)

Next to eradication of infection, bone graft supplementation is the most important supporting aspect in the treatment of nonunions. Application of autogenous bone graft, particularly iliac crest, remains the gold standard and most common method for treating bone defects as it exhibits all components necessary for successful bone augmentation including osteoinductive and angiogenic growth factors, living osteogenic osteoblasts and an osteoconductive bone matrix.(14) Iliac crest harvesting is, however, not without complications and RIA provides an excellent, minimally invasive source of autograft while providing ample graft volume without compromising biomechanical properties of the harvest location. $(13,15,16)$ RIA of the tibia is an elegant harvesting technique for use in primary intramedullary nail TTC arthrodesis.(17) This was, however, not an option in this case due to lack of remaining bone stock in the previously reamed tibia and a potential risk of dissemination in the setting of chronic osteomyelitis. The Masquelet technique has been shown to enhance non-union fracture consolidation due to the prevention of fibrous ingrowth, and promotion of an 
osteoinductive, vascularized scar tissue.(18-20) It has become a popular treatment modality in non-union fracture care, especially in the setting of bone defects.(21) It has also been used in hindfoot reconstruction with Huffmann et al. reporting good results in combination with RIA harvested autograft.(22) In this case, an external ring fixator was used to improve the chance of infection eradication by removing all hardware about the ankle and to more effectively compress the arthrodesis. Biomechanical studies have shown more lasting compression with external fixators versus arthrodesis nails, which may not maintain sustained compression.(23-26) Antibiotic-coated nails have also shown good rates of fusion in the setting of low-grade infections and would also have been a valid option.(27) However, we felt comfortable with the ring fixator in this case as it provides excellent stability and compression of the arthrodesis.

Fusion in this difficult case was achieved through the combination of infection eradication and osteoinductive potential provided by the Masquelet technique, the superior properties of RIA harvested autogenous cancellous bone graft, removal of all implants at the operative site, good hindfoot stability and compression provided by the ring fixator and a conservative postoperative management regimen with restricted weight-bearing for three months and a prolonged course of immobilization for six months.

\section{CONCLUSION}

In this case report, TTC fusion in the setting of chronic osteomyelitis years after a severe third degree open ankle fracture-dislocation was achieved using a staged Masquelet technique with stabilization through an external ring fixator and bone graft reconstruction including femoral harvested autograft using RIA. To our knowledge this technique has not been described before. Despite multiple 
revisions after failed ORIF and subsequent failed fusion, radiographic fusion was

quickly achieved and mobility markedly improved by six month follow-up. This

reconstructive salvage technique may be helpful in complex TTC arthrodesis in

the setting of a significant bony defect due to chronic osteomyelitis.

\section{REFERENCES}

1. Papa JA, Myerson M. Pantalar and tibiotalocalcaneal arthrodesis for post-traumatic osteoarthrosis of the ankle and hindfoot. JBJS 74: 1042, 1992

2. Goebel M, Gerdesmeyer L, Mückley T, Schmitt-Sody M, Diehl P, Stienstra J, Bühren V. Retrograde intramedullary nailing in tibiotalocalcaneal arthrodesis: a short-term, prospective study. The Journal of foot and ankle surgery 45: 98, 2006

3. Goebel M, Mückley T, Gerdesmeyer L, Militz M, Bühren V. Intramedullary nailing in tibiotalocalcaneal arthrodesis. Der Unfallchirurg 106: 633, 2003

4. Chou LB, Mann RA, Yaszay B, Graves SC, McPeake III WT, Dreeben SM, Horton GA, Katcherian DA, Clanton TO, Miller RA. Tibiotalocalcaneal arthrodesis. Foot \& ankle international 21: 804,2000

5. Millett PJ, O'Malley MJ, Tolo ET, Gallina J, Fealy S, Helfet DL. Tibiotalocalcaneal fusion with a retrograde intramedullary nail: clinical and functional outcomes. American journal of orthopedics (Belle Mead, NJ) 31: 531, 2002

6. Ochman S, Evers J, Raschke MJ, Vordemvenne T. Retrograde nail for tibiotalocalcaneal arthrodesis as a limb salvage procedure for open distal tibia and talus fractures with severe bone loss. The Journal of Foot and Ankle Surgery 51: 675, 2012

7. Nagashima M, Tachihara A, Matsuzaki T, Takenouchi K, Fujimori J, Yoshino S. Follow-up study of ankle arthrodesis in severe hind foot deformity in patients with rheumatoid arthritis using an intramedullary nail with fins. Modern rheumatology 15: 269, 2005

8. Morrey B, Wiedeman JG. Complications and long-term results of ankle arthrodeses following trauma. The Journal of bone and joint surgery American volume 62: 777, 1980

9. Carrier DA, Harris CM. Ankle arthrodesis with vertical Steinmann's pins in rheumatoid arthritis. Clinical orthopaedics and related research: 10, 1991

10. Ebraheim NA, Elgafy $\mathrm{H}$, Stefancin JJ. Intramedullary fibular graft for tibiotalocalcaneal arthrodesis. Clinical Orthopaedics and Related Research $\circledast$ 385: 165, 2001

11. Amirfeyz R, Bacon A, Ling J, Blom A, Hepple S, Winson I, Harries W. Fixation of ankle fragility fractures by tibiotalocalcaneal nail. Archives of orthopaedic and trauma surgery 128: 423, 2008

12. Anderson T, Linder L, Rydholm U, Montgomery F, Besjakov J, Carlsson Å. Tibiotalocalcaneal arthrodesis as a primary proce-dure using a retrograde intramedullary nail: $A$ retrospective study of 26 patients with rheumatoid arthritis. Acta orthopaedica 76: 580, 2005 13. Hammett R, Hepple S, Forster B, Winson I. Tibiotalocalcaneal (hindfoot) arthrodesis by retrograde intramedullary nailing using a curved locking nail. The results of 52 procedures. Foot \& ankle international 26: 810, 2005

14. Pape HC, Evans A, Kobbe P. Autologous bone graft: properties and techniques. Journal of orthopaedic trauma 24: S36, 2010

15. Newman JT, Stahel PF, Smith WR, Resende GV, Hak DJ, Morgan SJ. A new minimally invasive technique for large volume bone graft harvest for treatment of fracture nonunions. Orthopedics 31, 2008

16. Pape H-C, Tarkin IS. Reamer irrigator aspirator: a new technique for bone graft harvesting from the intramedullary canal. Operative Techniques in Orthopaedics 18: 108, 2008

17. Cuttica DJ, DeVries JG, Hyer CF. Autogenous bone graft harvest using reamer irrigator aspirator (RIA) technique for tibiotalocalcaneal arthrodesis. The Journal of Foot and Ankle Surgery 49: 571,2010

18. Masquelet A, Fitoussi F, Begue T, Muller G. Reconstruction des os longs par membrane induite et autogreffe spongieuse. In: Annales de chirurgie plastique et esthétique, pp. 346, Elsevier Masson. 2000. 
19. Pelissier P, Martin D, Baudet J, Lepreux S, Masquelet A-C. Behaviour of cancellous bone graft placed in induced membranes. British journal of plastic surgery 55: 596, 2002

20. Pelissier P, Masquelet A, Bareille R, Pelissier SM, Amedee J. Induced membranes secrete growth factors including vascular and osteoinductive factors and could stimulate bone regeneration. Journal of orthopaedic research 22: 73, 2004

21. Stafford PR, Norris BL. Reamer-irrigator-aspirator bone graft and bi Masquelet technique for segmental bone defect nonunions: a review of 25 cases. Injury 41: S72, 2010

22. Huffman LK, Harris JG, Suk M. Using the bi-masquelet technique and reamer-irrigatoraspirator for post-traumatic foot reconstruction. Foot \& ankle international 30: 895, 2009 23. Mückley T, Eichorn S, Hoffmeier K, Oldenburg Gv, Speitling A, Hoffmann GO, Bühren V. Biomechanical evaluation of primary stiffness of tibiotalocalcaneal fusion with intramedullary nails. Foot \& ankle international 28: 224, 2007

24. Mückley T, Hoffmeier K, Klos K, Petrovitch A, Von Oldenburg G, Hofmann GO. Angle-stable and compressed angle-stable locking for tibiotalocalcaneal arthrodesis with retrograde intramedullary nails: biomechanical evaluation. JBJS 90: 620, 2008

25. Yakacki CM, Khalil HF, Dixon SA, Gall K, Pacaccio DJ. Compression forces of internal and external ankle fixation devices with simulated bone resorption. Foot \& ankle international 31: 76 , 2010

26. Rochman R, Hutson JJ, Alade O. Tibiocalcaneal arthrodesis using the llizarov technique in the presence of bone loss and infection of the talus. Foot \& ankle international 29: 1001, 2008 27. Miller J, Hoang V, Yoon RS, Liporace FA. Staged treatment of infected tibiotalar fusion using a combination antibiotic spacer and antibiotic-coated intramedullary nail. The Journal of Foot and Ankle Surgery 56: 1099, 2017

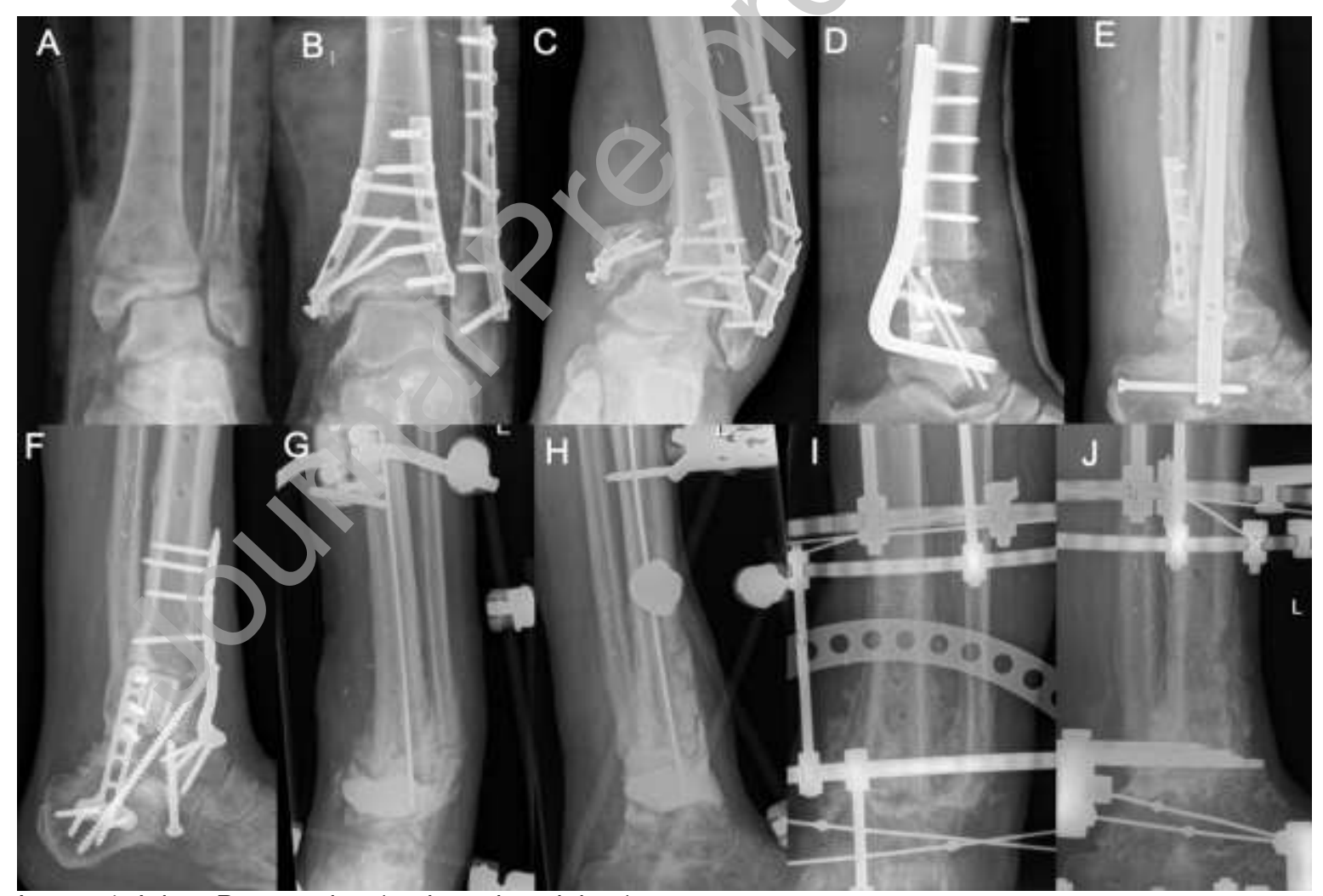

Image 1: Injury Progression ( $\mathrm{t}=$ time since injury)

A: initial post injury; $\mathrm{B}$ : after initial ORIF ( $\mathrm{t}=7$ weeks); $\mathrm{C}$ : hardware failure and loss of reduction ( $\mathrm{t}=6$ months); $\mathrm{D}:$ 95-degree blade-plate arthrodesis with allograft ( $\mathrm{t}=8$ months); $\mathrm{E}$ : $\mathrm{S} / \mathrm{P}$ revision with an arthrodesis nail ( $\mathrm{t}=21$ months); $\mathrm{F}: \mathrm{S} / \mathrm{P}$ revision with arthrodesis plates ( $\mathrm{t}=36$ months); G$\mathrm{H}$ : Masquelet revision ( $\mathrm{t}=45$ months); I-J: S/P final revision with ring-fixator and RIA autograft ( $\mathrm{t}=46$ months) 


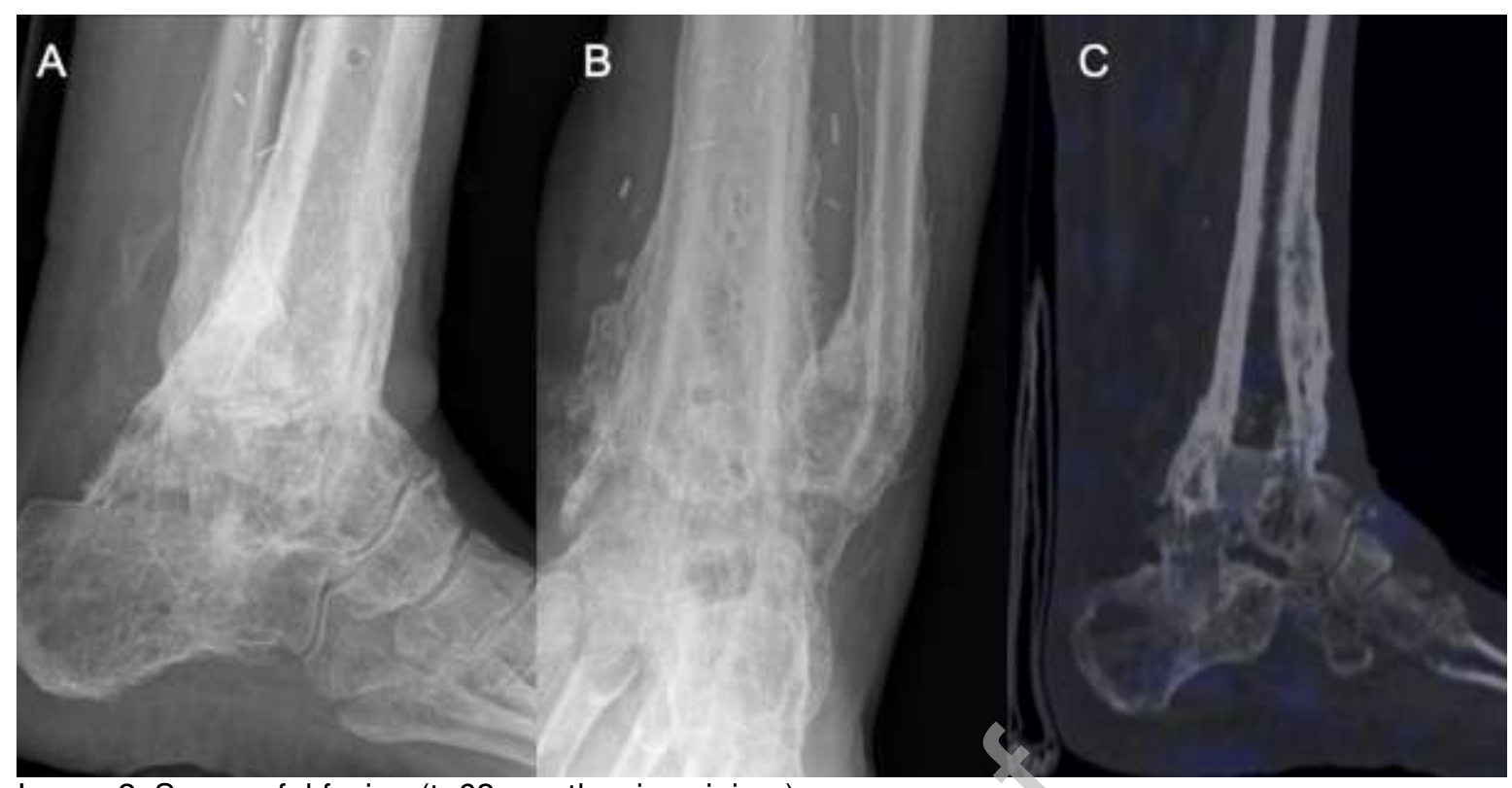

Image 2: Successful fusion ( $\mathrm{t}=62$ months since injury)

A: lateral radiograph; B: ap radiograph; C: SPECT CT showing eradication of infection

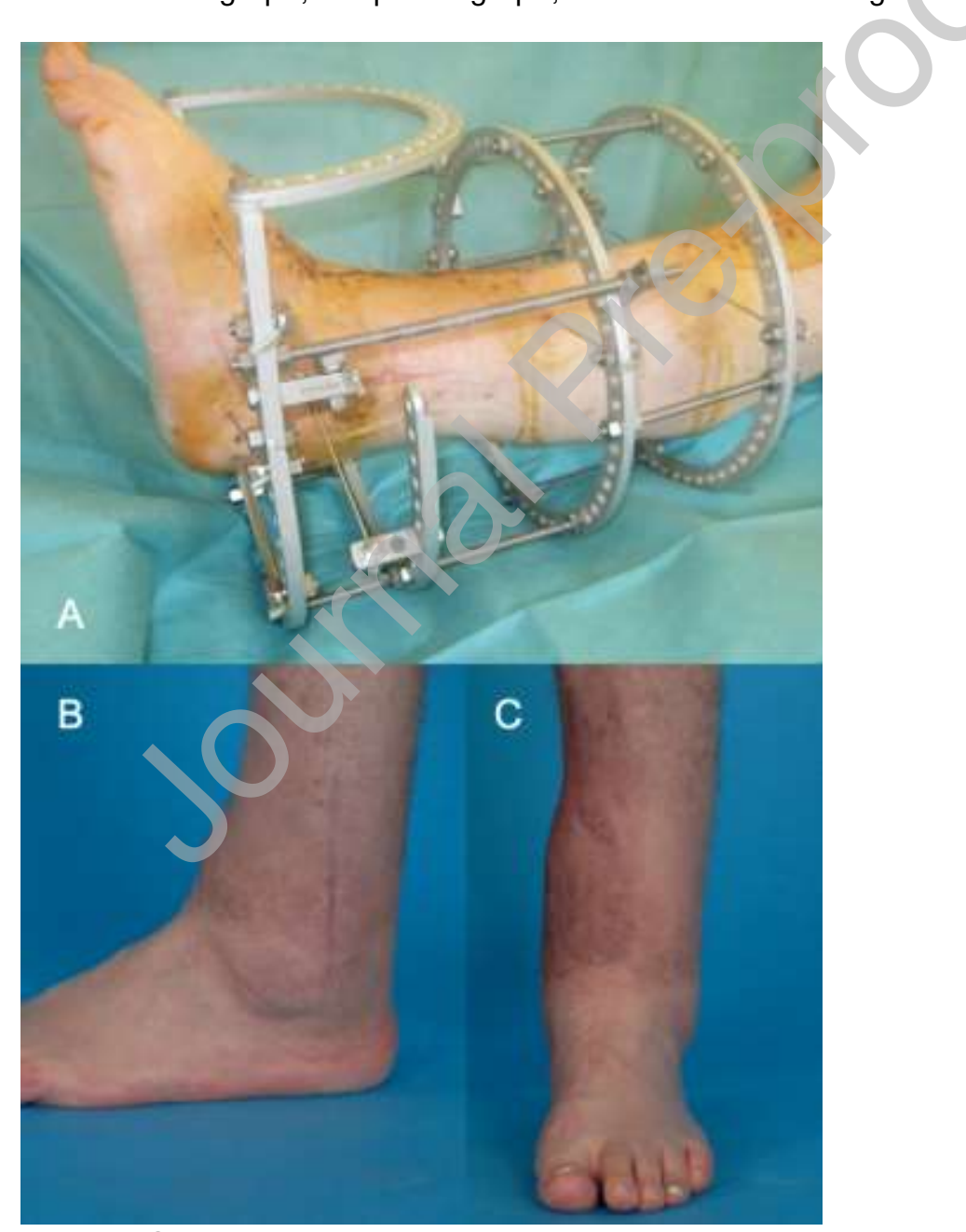

Image 3: Soft-tissues ( $\mathrm{t}=$ time since injury)

A: application ring-fixator ( $\mathrm{t}=46$ months); $\mathrm{B}-\mathrm{C}$ : soft tissues at follow-up ( $\mathrm{t}=62$ months) 


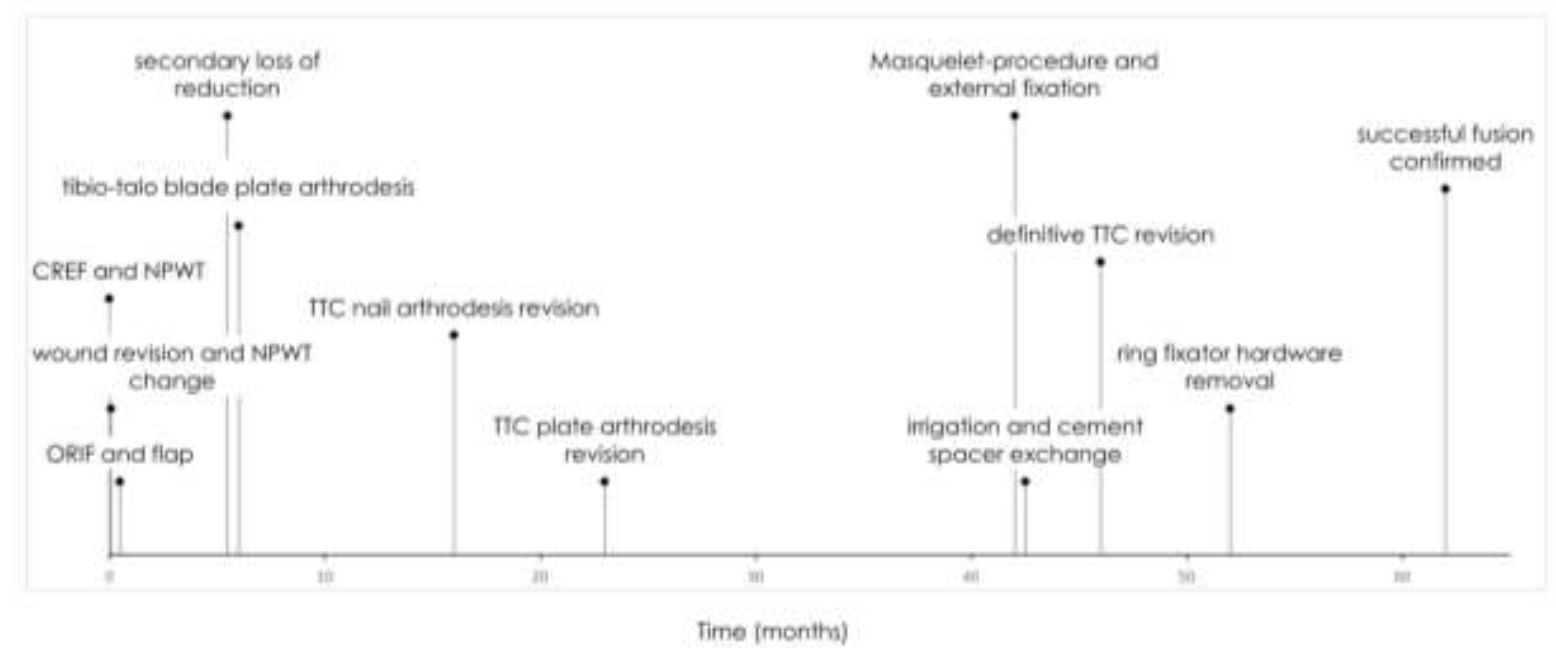

Figure 1: Clinical course timeline (in months since injury) 